\title{
A Student Primer On How to Thrive in Post-COVID-19 Engineering Education
}

\author{
Junaid Qadir ${ }^{1}$, Ala Al-Fuqaha ${ }^{2}$ \\ ${ }^{1}$ Information Technology University, Lahore, Pakistan \\ ${ }^{2}$ Hamad bin Khalifa University, Doha, Qatar; Western Michigan University, USA.
}

\begin{abstract}
In this paper, we strive to provide a primer for students on how to thrive and learn effectively in engineering education in the volatile, uncertain, complex, and ambiguous (VUCA) times following the onset of the COVID-19 global pandemic, which has disrupted the educational enterprise massively with universities physically closing in many parts of the world and students and faculty transitioning to remote learning. While our immediate focus in this paper is on engineering education functioning in an outcome-based education (OBE) environment, the global paradigm mandated by the Washington Accord that aims to standardize engineering competencies in terms of the attained student learning outcomes, our ideas are general and broadly useful for learners of all types. We will describe seven evidence-based steps that the students can adopt to thrive in OBE settings in these challenging times. The main contribution of this paper is practical: we present a synthesis of the vast research literature on effective student learning in normal, online, and disrupted settings to present practical insights that students can leverage to substantially improve their learning.
\end{abstract}

\section{INTRODUCTION}

The COVID-19 pandemic, the biggest one since the Spanish Flu of 1918, is the biggest global pandemic for the last 100 years. Educational institutes the world over have physically closed with students and faculty transitioning to distance learning and working from home. With this drastic change, students and faculty members face an unprecedented challenging situation. As the world continues an ongoing battle with the COVID-19 pandemic, our daily lives and routines have changed dramatically. The fallout of the pandemic is yet to fully play out but it is fair to say that whilst the education sector has been jolted by this pandemic, it has not been brought to its feet due to the Internet and the online education revolution. The year 2020 might well be a turning point in the history of educationin which the forced conversion of many traditional courses to online environments may be a fillip to the longer-term adoption of online and blended learning models.

In this paper, we aim to provide a primer for engineering students on how to thrive in an outcome-based education (OBE) environment in post-COVID-19 times. Some experts refer to the wide adoption of OBE as one of the top five major changes in engineering education in the last 100 years [1] especially with OBE being the underlying paradigm followed by global accreditation efforts such as the Washington Accord. OBE is considered the brainchild of the sociologist William Spady [2] [3], who defined "outcome" as a "culminating demonstration of learning" where demonstration is to be seen in the learner actually doing (e.g., describe, explain, design,

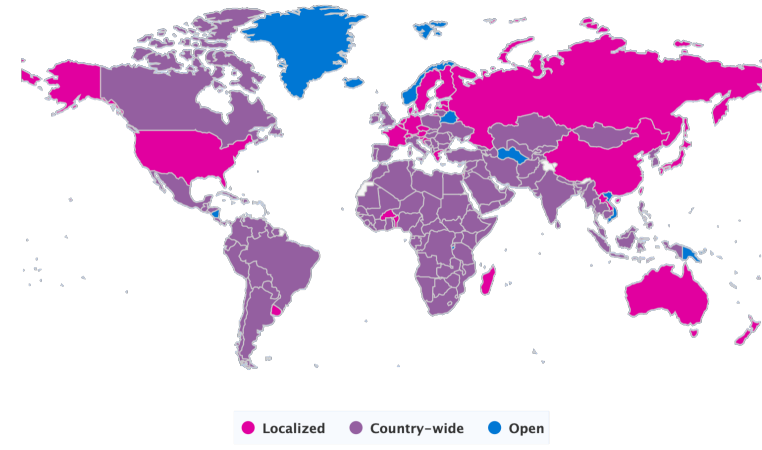

Figure 1: The global school shutdown effect caused by COVID-19 with 1,210,295,995 affected learners; $69.1 \%$ of total enrolled learners; 156 country-wide closures as of 18th May 2020 (Source: UNESCO [https://en.unesco.org/covid19/educationresponse]).

construct, produce, negotiate, operate) something tangible, visible, and observable with the curricular concepts. In the OBE paradigm, the instructional and assessment/evaluation practices are explicitly designed for ensuring the attainment of predefined learning outcomes that are aligned to broader, long-term educational objectives. More pertinently for students and teachers, the modern outcome-based education paradigm is rooted in the same philosophy and operates by focusing on molding instruction and assessment according to the preplanned educational objectives and learning outcomes.

The paper is timely due to the massive disruption to the education sector caused by the COVID-19 pandemic, the gravest global health crisis the world has seen in the last 100 years, with $85 \%$ of the countries around the world closing their educational institutes resulting in more than 1.6 billion students being out-of-school (per statistics reported in a April 2020 report [4]). With remote teaching and online learning becoming the norm, the onus has shifted onto the learners to take charge of their learning. We acknowledge that there are various factors outside the control of the students (e.g., the pedagogical approach adopted by the instructor and digital divide issues related to access to technology for connectivity and computing). However, we argue that there is much more that students can achieve than is commonly believed.

We stress that the purpose of this paper is entirely practical: we strive to present a primer for students on how they can thrive in such disrupted environments by synthesizing well-known 
insights reported in literature. While the other areas are also equally important, our focus in this paper is almost exclusively on what the students can do. Keeping in view the acceptance of practical and interdisciplinary articles in this journal, the authors would like to broadly disseminate these ideas to students so that they can leverage these well-established yet not widelyknown learning ideas and strategies to thrive in a disruptive environments such as the Post-COVID-19 environment.

Table I: Seven Steps to Thriving in (Post-COVID19) OBE

Step 1): Begin With The End In Mind (§II)

A: Knowing The Educational Objectives and Learning Outcomes

B: Aligning Effort With Goals, Objectives, and Outcomes

C: Motivation, Self-Efficacy, and Learning How to Prioritize

Step 2): Upgrade Your Metacognitive Skills (§III)

A: Types and Levels of Learning

B: Avoiding Common Learning Mistakes

C: Learning 101: Learning How To Learn

Step 3): Aim for Holistic Learning (§IV)

A: Become A System Thinker

B: Building A Lattice Work of Models

C: Be Well-Rounded

Step 4): Become Coachable ( $(\mathrm{V})$

A: Seek Formative Assessment

B: Learn to Think Like An Assessor

C: Develop Self-Assessment Skills

Step 5): Take Ownership of Learning (§VI)

A: Active Learning

B: Leverage What Can Be Leveraged

C: Collaboration \& Teamwork

Step 6): Focus On Developing Authentic Skills (§VII)

A: Develop An "Understanding" of the "Big Ideas"

B: Transfer of Learning

C: Uncoverage Rather than Coverage

Step 7): Become a Lifelong Learner (§VIII)

A: Develop A Mindset For Continuous Lifelong Learning

B: Master The Instrumental Knowledge For Lifelong Learning

C: Develop by Practice the Skills for Lifelong Learning

We structure our paper by describing the seven main steps that students can taken to thrive in a post-COVID-19 OBE environment (see Table I), each step in a different section ( $§ I$ to $\S$ VIII). Even though our focus is on engineering students, most of the ideas are general and also apply more broadly. We finally conclude the paper in $\S X$.

\section{Step 1: Begin With The End in Mind}

"To 'Begin with the End in Mind' means to start with a clear understanding of your destination. It means to know where you're going so that you better understand where you are now and so that the steps you take are always in the right direction" [5].

The economist Hal Varian, the author of multiple best-selling books and chief economist of Google, as part of his article on how to write successfully ${ }^{1}$, recounts that the best advice he ever got about writing a textbook was from the Turing Award winner" ${ }^{2}$ Richard Hamming, who said, "Get together the exercises and exams that you expect the students to be

\footnotetext{
${ }^{1}$ http://people.ischool.berkeley.edu/ hal/Papers/writing-economics.html

${ }^{2}$ The highest award in computer science considered similar in honor to the Nobel prize.
}

able to solve once they've read your book, then write the book that shows them how to solve them. The great thing about this advice is that it focuses you on the outcome you want to produce." This is excellent advice of course, but not only for textbook writers. This advice is equally beneficial for educators and there has been a mass shift in educational circles towards the upfront articulation of important objectives and outcomes and the design of instruction and assessment according to it. We discuss these ideas next.

\section{A. Knowing The Educational Objectives and Learning Out- comes}

" We cannot say how to teach for understanding or which material and activities to use until we are quite clear about which specific understandings we are after and what such understandings look like in practice."-Wiggins and McTighe [6]

Each educational endeavor (course, diploma, or degree) should have a clear end and the learning efforts of students should be focused on achieving these ends. These ends, depending on their time frame, are variously named as objectives and outcomes. In particular, 'objectives' are envisioned for the long-term where 'outcomes' are expected to be demonstrated at the time of the completion of the program or course. In OBE terminology, the most important objective-related term is program educational objectives (PEOs). When we come to outcomes, there are two principal types of outcomes: (1) program learning outcomes (PLOs) and (2) course learning outcomes (CLOs) [3]. These terms are sometimes unfortunately used interchangeably but we note these distinctions as they are commonly understood in the OBE paradigm. We describe these terms next.

- Program Educational Objectives (PEOs): PEOs are broad statements that describe what graduates are expected to attain within a few years of graduation (and unlike the following two outcomes, these objectives are not necessarily expected at graduation time).

- Program Learning Outcomes (PLOs): PLOs are statements that describe what students are expected to know and be able to do by the time of graduation. PLOs are at some places referred to as graduate attributes (GAs) [in the Washington Accord] or as student outcomes (SOs) [e.g., with ABET].

- Course Learning Outcomes (CLOs): CLOs refer to what students should be able to know, do, and value by the end of a course. CLOs are alternatively referred to as intended learning outcomes (ILOs) [e.g., in the UK] and subject learning outcomes (SLOs) [e.g., at Malaysia and Hong Kong].

Two other terms are commonly used in OBE based accreditation: vision and mission. These are more related to the institute's purpose and its continuous quality improvement (CQI) process. The vision statement refers to the future that the institute envisions for itself and concisely describes its values and ultimate purpose. The mission statement, while closely related to the vision statement, provides a more detailed direction for its present and future. The related term values describes 
the principles upon which the institution seeks to achieve its vision and fulfill its mission. The intimate relation/interaction between the vision-mission-objectives (VMO) and outcomes can be seen in Figure 2.

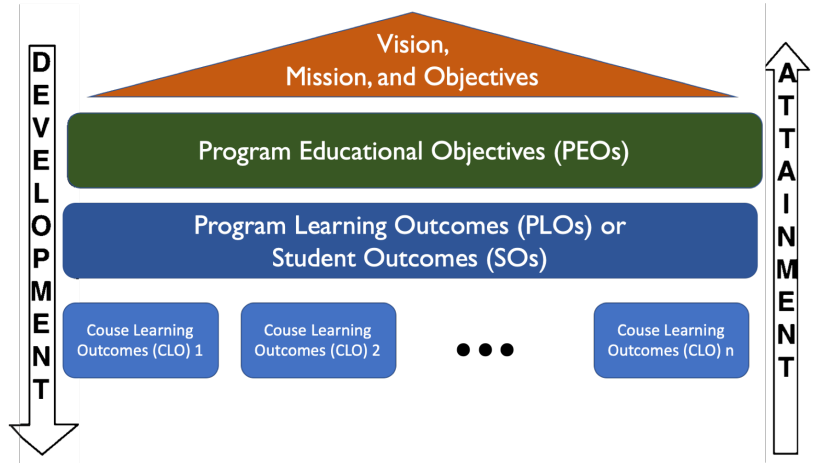

Figure 2: The outcomes pyramid. The desired outcomes towards the bottom are developed and shaped by those listed above. Also, the attainment of the bottom outcomes are necessary for attaining the outcomes/objectives listed on top.

\section{B. Aligning Effort With Goals, Objectives, and Outcomes}

"The main thing is to keep the main thing the main thing."-Stephen Covey [5]

The word align derived from the French word aligner ("to put in line") has the connotation of arranging scattered elements such that they function as a whole that has a common purpose [7]. It is important for all learners to not lose track of the big picture and to align their efforts with the end goal. This alignment of teaching, learning, and assessment with the planned learning outcomes is an accepted pedagogical best practice (e.g., as recommended by the Biggs's theory of Constructive Alignment [8]), which is especially needed in times of disruption as we have in the post-COVID-19 environment to avoid wasted effort.

\section{Motivation, Self-Efficacy, and Learning How to Prioritize}

"Explore the world. Nearly everything is really interesting if you go into it deeply enough."-Richard Feynman.

Stanford psychologist Albert Bandura called a person's belief system, or the personal conviction of what a person can do, "self-efficacy." In Henry Ford's words, 'Whether you think you can, or you think you can't-you're right.' Bandura showed that people high self-efficacy aimed higher, and correspondingly tried harder, preserved more, and showed more resilience in the face of failure. As argued in the work [9] to learn well, one must work with zest, invest effort into learning, recognize and resist the illusions of learning (such as confusing fluency with mastery), and use optimal learning techniques such as retrieval test.

Stanislas Dehaene in his book "How We Learn" [10] describes attention as a pillar of learning and describes how by paying attention one locks on the human perception system on to a thing of interest allowing neural circuits to select, amplify, and propagate the signals we perceive as relevant increasing our learning efficient multifold. A successful student should learn how to prioritize and learn where to focus attention. In this regard, a student would do well to see the learning outcomes for the program, course, and the lesson, and plan accordingly. The student can look for the assessment criteria and rubrics that can shed light on how the outcomes will be assessed and plan and allocate time accordingly. Ruthless prioritization according to this criteria is often quoted to be the key to outstanding academic performance without burning out [11].

\section{Step 2: Upgrade Your Metacognitive Skills}

"One of the most important aspects of cognition is metacognition-the process of reflecting on and directing one's own thinking".

Metacognition-the ability to know one's thinking, to selfevaluate, to mentally simulate what would happen if one thought this way or that way, and the limits of one's thinkingplays a fundamental role in human learning. The teaching of metacognition is listed as the most successful educational intervention in a website put together by the British Education Endowment Foundation (EEF), ${ }^{3}$ where this intervention is described as high impact for very low cost, based on extensive evidence. This is because our mindset, or our belief system, fundamentally affects our actions, goals, and perception.

To enhance our metacognition and to acquire an improved understanding of our cognitive mental processes, the students are recommended to have a basic working knowledge of the advances in cognitive and educational psychology [12], [13] and the learning sciences [14], [15], [10]. For example, students should know that learning is created in the brains when neurons are stimulated to form connections of neurons called synapses. These synapses are strengthened when that concept is retrieved. With thicker synapses, recalling memory becomes faster and clearer. Therefore to retain a memory it is important to not only understand a concept once but to retrieve the memory periodically (e.g., by recalling the ideas after some time or through testing). Effective learning is effortful-i.e., learning that involves conscious effort is more long-lived [13]. On the flip side, effortless learning or fluency with a topic can create a dangerous illusion of mastery that can vanish into thin air unless the topic is strengthened through an effortful engagement-e.g., through retrieval practice. Previous research has shown that strategies that involve some effort is better than cognitively effortless exercises (e.g., it is better to practice retrieval or attempt an explanation to others for long-term retention compared to passive rereading or rewatching content) [13], [9]. Experts have also figured out other details related to learning that were previously not as well known such as the importance of sleep for the consolidation of memories and the positive role exercise plays in enhancing cognitive performance.

\footnotetext{
${ }^{3}$ https://tinyurl.com/EEFTeachingLearningToolkit
} 


\section{A. Types and Levels of Learning}

"By educational objectives, we mean formulation of the ways in which students are expected to be changed by the education process. That is, the ways in which they will change in their thinking, their feelings, and their actions."-Bloom et al. [16].

Most people will agree that learning success should not be measured just in the ability to remember-more importantly, we should focus on what the student can do with the knowledge. The most important skills of the 21 st century (the so-called 21 st century skills) are the non-routine creative skills and competencies-including skills for critical thinking, creativity, collaboration, communication, and metacognition. There is, therefore, a need to move away from an overriding focus on knowledge acquisition (which is now a web search away for most humans) and focus more on higher-order cognitive skills (such as the ability to understand, apply, synthesize, evaluate, and create). Furthermore, there is a need to emphasize the affective domain (dealing with emotions and feelings) and psychomotor domain (dealing with the hands-on motor skills) in addition to the traditional emphasis on cognitive skills. In this regard, Bloom's taxonomy and its revisions serve as the most popular de facto benchmark of levels of educational outcomes and objectives. In this section, we will introduce this taxonomy of learning outcomes to enhance student's awareness of levels of learning.

1) (Revised) Bloom's Taxonomy: Bloom's taxonomy broadly refers to hierarchical models of educational objectives (or learning outcomes in modern OBE terminology ${ }^{4}$ ). These objectives are commonly organized in three hierarchies: corresponding to the cognitive, affective, and psychomotor domains roughly corresponding to knowledge, attitudes (or emotions), and skills. These models are named after Benjamin Bloom who chaired a committee of educators that devised the taxonomy [16] after years of consultation and deliberation. A revision of the taxonomy was performed in 2001 by Anderson and Krathwohl and we refer to this Revised Bloom's Taxonomy (Anderson and Krathwohl, 2001 [17]) in the remainder of the section.

2) Four Types of Knowledge: Anderson and Krathwohl's taxonomy [17] defines knowledge domain separately from the cognitive process domain and divides the former (i.e., knowledge domain) into four types of knowledge: factual, conceptual, procedural, and metacognitive.

- Factual knowledge refers to the basic knowledge students must know to be acquainted with a discipline or to solve a problem in that discipline.

- Conceptual knowledge refers to the interrelationship between the basic facts forming a bigger conceptual structure.

- Procedural knowledge refers to knowledge that relates to doing something and using developing skills, methods, techniques, and algorithms.

- Metacognitive knowledge involves broad knowledge of cognition in general as well as self-awareness.

\footnotetext{
${ }^{4}$ The term educational objectives was used by Bloom et al. beginning in 1956 and the term is akin to the modern OBE term "learning outcomes".
}

3) Cognitive Activities: "Cognitive" process activities include remembering and recalling knowledge, thinking, problem solving, creating. The Revised Bloom's taxonomy [17] defines six level of increasingly sophisticated objectives in the cognitive process domain. In the revised version of taxonomy, the levels are known by the following verbs (base layer to higher layers): (1) remember; (2) understand; (3) apply; (4) analyze; (5) evaluation; and (6) create. An illustration of these learning objectives arranged in the form of a hierarchical pyramid can be seen in Figure 3 while a detailed description of what these levels can be seen in Figure 4.

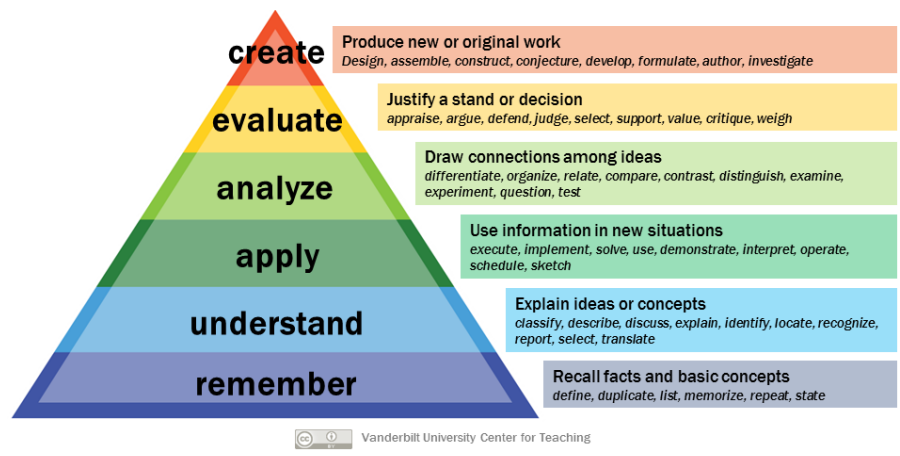

Figure 3: Bloom's Revised Taxonomy (2001) for the cognitive domain [Credit: Vanderbilt University Center for Teaching]

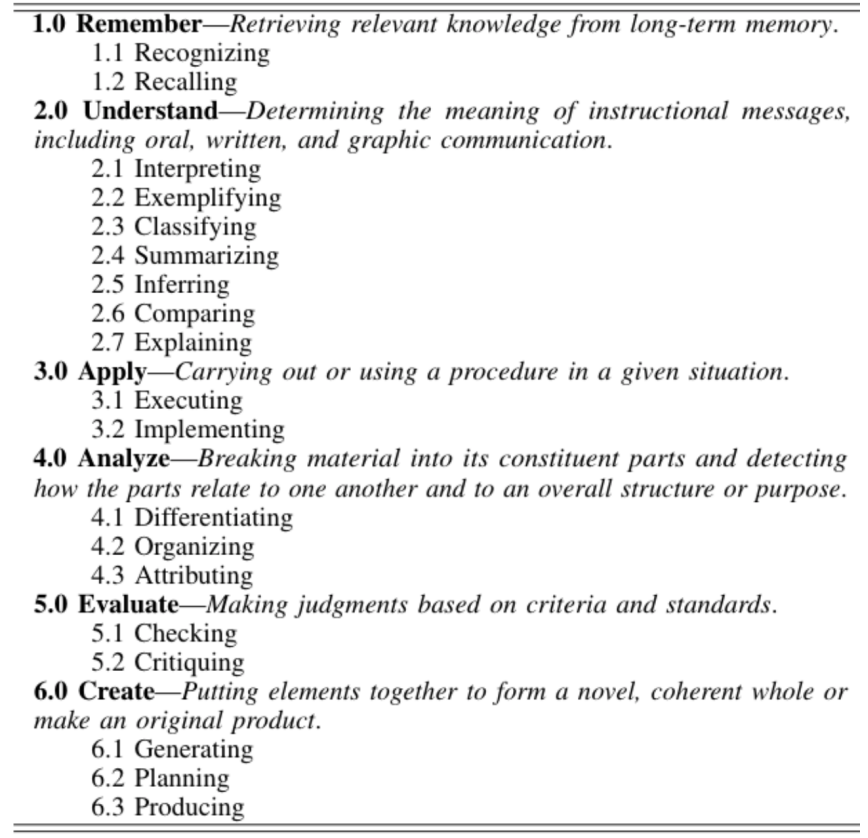

Figure 4: Structure of the Cognitive Process Dimension of the Revised Taxonomy (2001) [17] (With Example Verbs Exemplifying Different Levels)

4) Affective (Emotion-based) \& Psychomotor (Actionbased) Activities: While it is common for some students to believe that academic success is all about cognitive competence and performance, experts have underlined the need for other types of learning activities and competencies. In particular, learning objectives belonging to the affective domain (dealing 
with objectives describing changes in interest, attitudes, and values, and the development of appreciations and adequate adjustment) and the psychomotor domain (dealing with physical activities related to manipulative or motor skill area, which describe hands-on skills) are deemed to be fundamental for effective learning. This has been recognized by educational experts and Bloom et al. also proposed a hierarchy of affective learning skills in their original taxonomy. The original taxonomy, however, did not propose a taxonomy for the psychomotor domain and the commonly used psychomotor domain taxonomy of learning skills was proposed in 1972 [18]. For students to thrive in OBE environments, it is important that they are aware of the different levels of learning objectives and that these objectives may relate to knowledge (cognitive domain), skills (psychomotor domain), or emotions or values (affect domain).

\section{B. Avoiding Common Learning Mistakes}

"To make no mistakes is not in the power of man; but from their errors and mistakes; the wise and good learn wisdom for the future."-Plutarch.

One way to become a good learning is via negativa-i.e., by avoiding common learning impediments. In a previous work [19], Qadir has summarized some information that all students should know: what are the seven most common learning impediments and how can these impediments be surmounted. More specifically, seven major learning impediments were identified: (1) having a fixed mindset; (2) the failure to engage oneself in learning; (3) the failure to manage time; (4) the failure to realize that paradoxically failing (i.e., making mistakes) is the key to learning; (5) the failure to realize that learning is a social activity; (6) being a learning monogamist (i.e., learning from only one source/viewpoint); and (7) not learning how to learn. The author also proposed three remedies for each of the seven learning impediment (which is summarized in Figure 5; with full details available at [19]).

\section{Learning 101: Learn How To Learn}

"Is there anyone so wise as to learn by the experience of others?"-Voltaire.

In the previous subsection, we discussed the via negativa approach: here we take the via positiva approach, which focuses on articulating some essential learning facts that are little known but have the power of vastly improving people's learning. A previous paper by Qadir \& Imran [9] took this approach and scoured through the learning sciences literature to find important insights. The paper highlighted the counterintuitive insights discovered in the literature (see a gist of the discussion in Table II) such as the fact that some difficulties are desirable in learning, and that not all learning fluencies are desirable, and finally talked about techniques (such as retrieval practice, spaced learning, interleaving, and aiming for mastery) that are very effective in practice. A general finding reported in the paper was that learning that is more effortful is also more durable and robust. The authors also made some evidence-based recommendations that go against conventional wisdom which we outline next (interested readers can see the full details in [9]).
Impediment 1) Having a Fixed Mindset

Solution: Conquer your mind to realize your potential.

Remedy I: Have a growth mindset

Remedy II: Aim for Mastery

Remedy III Using Intrinsic Motivation

Impediment 2) the Failure to Engage 'Yourself' in Learning

Solution: Knowledge will not give a part of itself until you give to it all of yourself.

Remedy I: Ask Questions

Remedy II: Study More Actively

Remedy III: Make Efforts to Enjoy the Subject

Impediment 3) the Failure to Manage Time

Solution: Until we can manage time, we can manage nothing else. Remedy I: Form Good Habits

Remedy II: Learn Mindfulness and the Art of Focusing

Remedy III: Practice Prioritization and Discipline

Impediment 4) Failing to Realize that Failing is Key

Solution: Err unabashedly and learn-like a child does.

Remedy I: Embrace Failure and Impediments

Remedy II: Make Peace with Confusion

Remedy III: Value Effort over Intelligence, and the Process over Extrinsic Reward

Impediment 5) Failing to Realize that Learning is Social

Solution: No one can do it for you, but you can't do it alone.

Remedy I: Have a Mentor

Remedy II: Seek Feedback

Remedy III: To Learn, Teach

Impediment 6) Being a Learning Monogamist

Solution: Encourage learning polygamy.

Remedy I: Avoid the Illusions of Learning

Remedy II: Seek Diverse Knowledge Sources

Remedy III: Adopt Diversity in Study Techniques

Impediment 7) Not Learning How to Learn

Solution: Don't be an highly qualified A grade sheep.

Remedy I: Develop Metacognitive Skills

Remedy II: Learn Critical Thinking

Remedy III: Become a Lifelong Learne

Figure 5: Common Learning Impediments and Their Remedies (Reproduced from [19])

1) Spaced out learning: instead of concentrating all your learning sessions together, you should space out your learning sessions over time.

2) Interleaving: instead of blocking practice sessions (i.e., revising one topic and then the other), practice interleaving (this will be more effortful but will help discriminate ideas resulting in more robust learning).

3) Testing: instead of rereading material, you should test yourself on the learned knowledge or practice mental retrieval.

4) Variety: instead of always learning in the same modality and environment, vary the conditions and the environmental context of your learning.

\section{Step 3: Aim for Holistic Learning}

"You don't understand anything until you learn it more than one way."-Marvin Minsky

\section{A. Become A System Thinker}

"We're blind to our blindness. We have very little idea of how little we know."-Daniel Kahneman.

To be a system thinker means to develop holistic thinking: i.e., to see any entity being studied not in isolation but as an entity related to other entities so that one can see the bigger 
Table II: Some guidance on how to learn from "Learning 101: The Untaught Basics" (Qadir and Imran, 2018 [9])

\begin{tabular}{|c|c|}
\hline Pointers & Explanatory Quote \\
\hline \multicolumn{2}{|l|}{ Desirable Difficulties: } \\
\hline $\begin{array}{l}\text { 1) Effortful learning is better } \\
\text { learning }\end{array}$ & $\begin{array}{l}\text { "Practice that's spaced out, interleaved with other learning, and varied } \\
\text { produces better mastery, longer retention, and more versatility. But these } \\
\text { benefits come at a price: when the practice is spaced, interleaved, and } \\
\text { varied, it requires more effort."-Brown, Roediger, and McDaniel [13] }\end{array}$ \\
\hline $\begin{array}{l}\text { 2) To learn, you must forget, } \\
\text { then interrupt forgetting }\end{array}$ & "It is only what breaks that grows."- Unknown \\
\hline $\begin{array}{l}\text { 3) Disfluency/discomfort can } \\
\text { be good for learning }\end{array}$ & "That which does not kill us makes us stronger." - Nietzsche \\
\hline \multicolumn{2}{|l|}{ Undesirable fixations: } \\
\hline $\begin{array}{l}\text { 1) Fixating on perfection: } \\
\text { Why mistakes are required }\end{array}$ & $\begin{array}{l}\text { "An expert is a man who has made all the mistakes which can be made, } \\
\text { in a narrow field."-Niels Bohr }\end{array}$ \\
\hline $\begin{array}{l}\text { 2) Fixating on fluency: Why } \\
\text { fluency is not sufficient }\end{array}$ & $\begin{array}{l}\text { "Rising familiarity with a text and fluency in reading it can create an } \\
\text { illusion of mastery."-Brown, Roediger, and McDaniel [13] }\end{array}$ \\
\hline $\begin{array}{l}\text { 3) Fixating on discipline: The } \\
\text { upside of variety }\end{array}$ & $\begin{array}{l}\text { "You don't understand anything until you learn it more than one way."- } \\
\text { Marvin Minsky }\end{array}$ \\
\hline \multicolumn{2}{|c|}{ For efficient learning, use optimal learning techniques: } \\
\hline $\begin{array}{l}\text { 1) Testing/retrieval practice as } \\
\text { a learning tool }\end{array}$ & $\begin{array}{l}\text { "In virtually all areas of learning, you build better mastery when you use } \\
\text { testing as a tool to identify and bring up your areas of weakness."-Brown, } \\
\text { Roediger, and McDaniel [13] }\end{array}$ \\
\hline $\begin{array}{l}\text { 2) Spaced learning and inter- } \\
\text { leaving }\end{array}$ & $\begin{array}{l}\text { "The truth is, nothing in learning science comes close [to spaced } \\
\text { learning] in terms of immediate, significant, and reliable improvements } \\
\text { to learning."-Benedict Carey [14] }\end{array}$ \\
\hline 3) Aiming for mastery & $\begin{array}{l}\text { "To be a sophisticated learner requires understanding that creating durable } \\
\text { and flexible access to to-be-learned information is partly a matter of } \\
\text { achieving a meaningful encoding of that information and partly a matter } \\
\text { of exercising the retrieval process."-Bjork, Dunlosky, and Kornell [20] }\end{array}$ \\
\hline
\end{tabular}

picture by fitting pieces of a system together to form a whole [21]. Systems thinking implies a move away from myopically viewing things in isolation but seeing how system components interact with each other through multi-loop nonlinear feedback: this enables system thinkers to study how interventions in complex adaptive systems can have unpredicted and unintended consequences. With systems thinking, one begins to realize that we see the world through mental models and that our mental models may not be perfectly aligned with reality and that we can think better through diverse models (also called many model thinking [22]). In terms of education, becoming a systems thinker helps one in seeing how our engineering artifacts affect the world and society in multifarious ways and in becoming better designers of technology that has net positive social implications.

Previous research indicates that engineering education does not adequately prepare students to address complex, illstructured, real-world problems, such as wicked problems such as sustainability, which has led to calls for systems-thinking based approaches. For example, the National Engineering Academy (NEA), USA, highlighted "a growing need for interdisciplinary and system-based approaches" in the report on educating the engineer of 2020 [23]. Such an approach will also help an engineer to appreciate the broad impacts of technological artifacts on the environment, society, and the economy.

\section{B. Building A Lattice Work of Models}

"You've got to have models in your head. And you've got to array your experience - both vicarious and direct - on this latticework of models."-Charlie Munger [24].

Engineering students should be, from the start, wary of a hubristic infatuation with a single model. George Box had famously said "all models are wrong, some are useful" to highlight the fact that models are useful in some contexts but should be equated with the entirety of the "truth" [25]. To believe that a single equation can always explain or predict real-world social phenomena is a failure to appreciate how unpredictable a complex adaptive system can be and how emergent behavior can develop in it. In the words of Noble prize winning physicist Richard Feynman, 'The world is much more interesting than any one discipline." When we do not encourage broad multidisciplinary learning, we develop blind spots of which we remain ignorant. We also run the risk of knowing no better than use inappropriate models at the wrong place for it is said that to a person having only one hammer, everything starts to appear like a nail.

\section{Be Well-Rounded}

"To rely on a single model is hubris. It invites disaster."-Scott Page [22].

In the history of engineering education, there has been a perennial search for the right tradeoff between breadth and depth, generalization and specialization, and liberal arts/sciences and vocational training. In a volatile, uncertain, complex, and ambiguous (VUCA) 21st-century world, the deal seems to have swung squarely in the half of breadth, generalization, and liberal arts/sciences due to (1) a dramatic expansion of knowledge, (2) a diminishing half-life of engineering knowledge, (3) expanding lifetimes [26]. Many efforts at engineering education reform aiming to change education for the 21 st century are proposing a focus on developing the diverse skills of the whole mind [27], [28], [29], [30]. Engineering education in the 21 st century requires both the quantitative and the qualitative. Engineers need to "understand and appreciate history, philosophy, culture, and the arts, along with the creative elements of all of these disciplines.". ${ }^{5}$ By becoming more well-rounded, Goldberg talks of engineering education being the new liberal arts since it includes important technological literacy that is essential in today's world [29]. There is also wide agreement that relying merely on the hard science of engineering is no longer enough to meet the 21st century challenges [31] (e.g. see National Academy of Engineering's report "The Engineer of 2020" [32]). In the book Rebel Ideas, the author Matthew Syed describe how narrow skills and lack of diversity leads to numerous problems-homophily, dominance dynamics, and echo chambers-which characterizes some troubling characteristics of the modern polarized world [33]. Apart from engendering a more humane and empathetic society, developing diversity and breadth brings about scholarly benefits such as encouraging innovation through the diffusion of ideas across disciplinary boundaries. However, breadth should not come at the cost of depth: modern engineers need to have deep expertise in some core engineering fields apart from broad knowledge in several fields (some authors refer to such learning as T-shaped learning [34]).

\section{Step 4: Become Coachable}

"Try to learn. Be coachable. Try to learn from everybody, especially those who fail."-David Foster Wallace

\footnotetext{
${ }^{5}$ https://www.chronicle.com/article/Engineers-Need-the-Liberal/240125
} 


\section{A. Seek Formative Assessment}

"As soon as students get a grade, the learning stops. We may not like it, but the research [...] shows that this is a relatively stable feature of how human minds work."-Dylan Wiliam

In formative assessment, in contrast to the commonly used summative assessment, the assessment's purpose is not to rank the students or to gauge their current learning per se; the explicit aim instead is to facilitate learning. Formative assessment, for this reason, is sometimes called assessment for learning (A4L) compared to summative assessment, which is called assessment of learning. In formative assessment, the current level of learning is assessed instrumentally so that pertinent feedback may be provided to both the student and the instructor so that they can take concrete steps to facilitate learning improvement. As an example, an instructor may dissect a student's response and highlight deficiencies and suggest avenues for improvement. Formative feedback is well suited to the OBE paradigm since it can be instrumental for the attainment of learning outcomes. It is well established in the literature [35], [36] that formative assessments have a powerful effect on student learning (particularly for weaker students). John Hattie noted in his book Visible Learning [37], based on a synthesis of more than 800 meta-analyses related to learning achievement, that "the most powerful single influence enhancing achievement is feedback." We have previously seen the key role growth mindset is key for enhancing learning performance. Armed with a growth mindset, a learner can benefit greatly by becoming more coachable [38] — by which we mean that learners develop the mindset and openness to seek, accept, and act on to (potentially critical) feedback, which provides the learner valuable perspective on how to improve. With this, the learner also imbibes a passion for self-improvement sowing the seeds for lifelong learning (the pivotal Step 7 of our framework).

\section{B. Learn To Think Like An Assessor}

"When students become their own teachers they exhibit the self-regulatory attributes that seem most desirable for learners (self-monitoring, self-evaluation, self-assessment, self-teaching)"-John Hattie.

Wiggins encourages students to think like an assessor and notes that this thinking eventually boils down to thinking about the following question: "what kinds of evidence do we need to find hallmarks of our goals, including that of understanding?' To align one's thinking with the overall assessment system being deployed, it helps if the learner can look critically through the assessment criteria and rubrics to see what kinds of evidence the instructor is seeking for the sought-after understanding. If the assessment criteria are unclear, the learner should immediately consult and discuss with the instructor for more clarity. This will allow the learner to plan activities and allocate time accordingly.

\section{Develop Self-Assessment Skills}

"When students become their own teachers they exhibit the self-regulatory attributes that seem most de- sirable for learners (self-monitoring, self-evaluation, self-assessment, self-teaching)"-John Hattie.

The use of formative assessment can substantially transform students' performance by equipping them with the empowering skills of "self-assessment" (through which students acquire the skill of judging and monitoring their levels of learning) and "self-directedness" (through which they become capable of deciding what they should do next to improve their learning and setting learning goals for oneself). Reflection on one's performance is a vital component of a learner's self-assessment skills. There are various reflection-oriented self-assessment drills that a learner can try for any subject and level. For example, a learner can reflect on his or her academic strengths, motivation, interests, learning preferences. A learner may train himself or herself on dispassionately assessing an assignment and evaluating it for its strength and weaknesses. This can be done both before and after the learning activity or assignment (pre- and post-reflection). Performing a pre-mortem on a project submission, or a post-mortem on a failed test, provide a great learning opportunity that can facilitate significant learning improvement [39].

\section{Step 5: Take Ownership of Learning}

"Learning results from what the student does and thinks and only from what the student does and thinks. The teacher can advance learning only by influencing what the student does to learn."-Herbert A. Simon.

\section{A. Active Learning}

"Converging results from diverse fields suggest that a passive organism learns little or nothing. Efficient learning means refusing passivity, engaging, exploring, and actively generating hypotheses and testing them on the outside world."-Stanislas Dehaene.

Stanislas Dehaene identifies four pillars of learning in his book "How We Learn": the first two of which- "Attention" and "Active Engangement"-relate to Active Learning. The first pillar, attention, describes how by paying attention one locks on the human perception system on to a thing of interest allowing neural circuits to select, amplify, and propagate the signals we perceive as relevant increasing our learning efficiency multifold. The second pillar, active engagement, refers to mental activity and engagement and describes that to learn we need motivation, curiosity, and an active generation of hypothesis and refinement of our mental models through engagement with the real world (the error feedback one receives in this process is extremely important and represents Dehaene's third pillar of learning). This means in the immediate online-learning-focused postCOVID-19 environment, it is important to not only listen to lectures but to periodically test oneself to recall ideas from our minds and to relate them to previously learned concepts to strengthen our learning.

\section{B. Leverage What Can Be Leveraged}

"Entrepreneurship is a mindset, an outlook that shapes the way you see the world and the possibilities that it holds." 
It is important for the 21st century engineer to be resourceful and entrepreneurial [40]. One manifestation of being resourceful is to realize that in life one does not have the luxury of changing everything on-demand-one ultimately can only play with the cards they are dealt with. However, it is up to the learner to devise the best strategy for fully benefitting from the opportunities available locally or globally. In the current era of globalization and open educational resources/courses, help is never far. One should leverage all the available resources. There are now offerings of various high-quality learning resources through massive open online courses (MOOCs) from various global and regional MOOC providers (e.g., Coursera, EdX, France Université Numérique, Edraak, FutureLearn) in different languages such as English, French, Spanish, German, Arabic, Chinese, etc [41]. Apart from these riches, students should not hestitate to ask for help from the human resources and experts accessible within their community (city, university, country). The late Apple founder Steve Jobs described how he leveraged the remarkable power of asking for help by calling Bill Hewett (the co-founder of Hewlett-Packard) for some smart parts to build a project that he was doing by looking up Hewett's number in the public phone directory. ${ }^{6}$ Steve Jobs not only got the parts but also a summer job at the company. Steve Jobs recalling this story remarked that "You gotta act. And you've gotta be willing to fail, ... if you're afraid of failing, you won't get very far." Students will do well to use the same idea by not hesitating in reaching out to faculty members, seniors, experts, and entrepreneurs, for help that can take them forward in their learning. The weaker students, in particular, stand to benefit significantly from gaining the courage to ask for help and to reach out to the various resources that they can access but paradoxically these students rarely ask for help, a fact that further exacerbates the divide between the top students and the lagging ones.

\section{Collaboration \& Teamwork}

"Critical thinking and problem solving, communication and collaboration, and creativity and innovation are three top-drawer skill sets in our toolbox for learning, work, and life in the 21st century."-Trilling and Fadel [42].

The benefits of collaborative learning are well established in literature through numerous studies with students learning in small-groups achieving higher grades, retaining information better, and acquiring great communication and team-work skills [43]. Such skills have become especially important in the $21 \mathrm{st}$ century [42], [44]. These benefits are not automatic though and optimally leveraging collaborative learning requires attention to techniques scientifically shown to be conductive for effective team learning from the instructor and the learners [43]. With numerous software available for group interaction (such as Google Meet, Microsoft Teams, Slack, etc.), there are plenty of technical solutions that can be used to aid facilitation among team members even in (post-)COVID-19 lockdown situations.

${ }^{6}$ https://tinyurl.com/JobsPowerOfAsking-Inc-com

\section{Step 6: Focus on Developing Authentic Skills}

"The most important method of education ... always has consisted of that in which the pupil was urged to actual performance."-Albert Einstein.

In the 21 st century, learners are expected to grapple and engage with complex open-ended problems that may defy simple solutions. It is no longer sufficient for learners to simply memorize information. Learners should be able to demonstrate learning and performance on authentic tasks (i.e., tasks that simulate realistic environments and problems that the learner would face in the real-world). According to Wiggins [45], a performance task, problem, or project, can be said to be 'authentic' if it: (1) is realistic; (2) requires judgment and innovation; (3) engages the learner in "doing" the subject; (4) replicates or simulates real-world contexts; (5) assesses a learner's ability to deal with an open-ended complex task by using a repertoire of knowledge and skills effectively; (6) does not put artificial constraints on opportunities to practice, consult resources, obtain feedback, and refine performance. The ability to work on actual real-life problems, particularly in groups, is a much valued skill that has motivated the development of pedagogical approaches such as Problem Based Learning (PBL) used in various universities (e.g., Aalborg university, Denmark [46]).

\section{A. Develop An “Understanding” of the "Big Ideas"}

"What we are claiming, based on both common sense and the research in cognition, is that no skill can be integrated into a powerful repertoire unless the learner understands the big ideas related to using the skill wisely."-Wiggins and McTighe [6].

Wiggins and McTighe in their best-selling "Understanding By Design" [6] distinguish the knowledge of experts from the knowledge of novices by noting that experts seek to develop an understanding of the problem in terms of the core concepts or the big ideas. Wiggins and McTighe describe an understanding as a transferable abstract big idea of enduring value going beyond a specific topic-mastering such an understanding allows for robust learning that allows transfer and application. Such an understanding has to be earned (i.e., it must be coconstructed by learners and developed inductively while "doing" the subject on authentic tasks in realistic settings). Wiggins and McTighe describe that learning big ideas economizes learning effort since these ideas are general and help organize many isolated bits of information coherently. In contrast, the knowledge of the novices is much more fragile since their knowledge is less likely to be organized around big ideas or interconnected. If an education only contains an unrelated collection of inert facts, it becomes, in the words of Alfred Whitehead, "not only useless" but "harmful." Due to this, experts can transfer their knowledge from one setting to another while novices find this very hard. In the words of John Dewey, "To grasp the meaning of a thing, an event, or a situation is to see it in its relations to other things: to see how it operates or functions, what consequences follow from it, what causes it, what uses it can be put to" [47]. 


\section{B. Transfer of Learning}

"Transfer must be the aim of all teaching in schoolit is not an option- because when we teach, we can address only a relatively small sample of the entire subject matter."-Wiggins and McTighe.

For 21 st century skills, instead of teaching and testing for memorization of facts and information, we need to aim for transfer, where transfer implies a capability of deep comprehension and application in novel settings [21]. The body of knowledge has become so vast these days that it is impractical for a university education to attempt to cover even in narrow specializations all the related knowledge. Instead the overarching aim should be to understand ideas and concepts of broad applicability deeply and then have the capability of applying these ideas in new settings. Transfer is the essence of what Bloom and his colleagues referred to as Application in their taxonomy of learning objectives. Unfortunately as Eric Mazur points out much of the current assessment practices focus on and encourages Remembering, which per Bloom's taxonomy is the lowest level of thinking skills [48].

\section{Uncoverage Rather than Coverage}

"Teaching [and learning] specific topics or skills without making clear their context in the broader fundamental structure of a field of knowledge is uneconomical." - Jerome Bruner

Without transfer learning, learning is fragile and students are incapable of generalizing concepts and in understanding their relationships. Without the development of transfer skills, students will not be able to understand a topic or subject and be able to use (or "apply," in Bloom's sense) knowledge and skill effectively. Wiggins recommends that learners should not only focus on "covering" topics as coverage can result in students being lost and alienated when they are unable to see the relationship of the covered topics but focus on "uncovering" the real issues lurking below the surface, and keep returning to them, as they consolidate and further their learning [6]. The conventional coverage of topics, according to the educator Jerome Bruner, is uneconomical since with coverage seeing the whole requires more and more effort as the topics begin to increase. A better approach would, in the words of the English philosopher Alfred Whitehead, be "let the main ideas which are introduced be few and important, and let them be thrown into every combination possible". In this way, the uncovering of the big ideas returns impressive results with frugal investment since the ideas learned are few in number but broadly applicable.

\section{Step 7: Become a Lifelong Learner}

"Give a man a fish, and you feed him for a day.

Teach a man to fish, and you feed him for a lifetime."

It is estimated that presently engineering knowledge has a doubling time, and information half-life (i.e., when half of the engineering information becomes obsolete), of roughly 5 10 years. $^{7}$ When we also consider the increased longevity of

\footnotetext{
${ }^{7}$ https://spectrum.ieee.org/view-from-the-valley/at-work/education/ the-engineers-of-the-future-will-not-resemble-the-engineers-of-the-past
}

lifetimes, it becomes clear to see why it is critical to teach to engineers the ability and instrumental knowledge and engender a mindset for continuous lifelong learning.

\section{A. Develop A Mindset For Continuous Lifelong Learning}

"Most of what our students need to know hasn't been discovered or invented yet. "Learning how to learn" used to be an optional extra in education; today, it's a survival skill."-Dylan Wiliam

Duderstadt in his proposal "Engineering for a Changing World" [49] proposed that the engineering profession should also "develop a structured approach to lifelong learning for practicing engineers similar to those in medicine and law. This will require not only a significant commitment by educators, employers, and professional societies but possibly also additional licensing requirements in some fields." Harvard and some other universities are even formalizing the so-called 60-year curriculum to chart a plan for a lifetime of learning [50]. In such an environment, it becomes important to develop a mastery mindset that is not satisfied with sitting on past laurels and knowledge but is well-tuned with a mindset that values and cherishes continuous new learning.

\section{B. Master The Instrumental Knowledge For Lifelong Learn- ing}

"They know enough who know how to learn."-Henry

Adams.

The ability to develop the capabilities of indistractablity or deep focus is very valuable in the 21 st century-especially in the context of post-COVID-19 online learning environments. Tackling procrastination and practicing self-discipline in such environments is harder but very helpful. Like other skills, one can better at focusing and concentrating periodically [51], [52], [53]. In a similar vein, when students acquire meta-skills such as learning how to learn, read, write, they bring this skill to every course and reap its exponential benefits-this effect is sometimes called the "Matthew Effect" [54] or the rich get richer and the poor get poorer effect. One should be committed therefore to investing time in developing oneself regularly.

\section{Develop by Practice the Skills for Lifelong Learning}

"Life is like riding a bicycle. To keep your balance you must keep moving."-Albert Einsten.

Moving into the third decade of the 21st century, the 2020s, the unprecedented rate of increase in knowledge, and the demands of being a 21 st century engineer [32], [26], requires us to keep moving. While it is true that the basics of engineering do not change overnight, the half life of engineering knowledge is rapidly receding and now the unchanging basics must be regularly complemented with new ideas and knowledge. This places a premium on the meta-skill of lifelong learning and therefore it becomes important to acquire this skill and get better at this through practice. This practice should begin early and should be exercised vigorously during the engineering degree so that the student is well placed to contribute and thrive in a dynamic future world. 


\section{DISCUSSION}

While effective education in such settings depends on various factors including state policies, pedagogical methods used by the instructors, and the wide availability of digital technologies, and these are important topics to explore, the scope of this paper is limited to what the student/learner can do.

\section{A. Effective Learning Techniques Are "Antifragile"}

"Some things benefit from shocks; they thrive and grow when exposed to volatility, randomness, disorder, and stressors and love adventure, risk, and uncertainty."-Nassim Nicolas Taleb [55].

Most of the learning strategies recommended in this paper are per se not directly related to engineering education. Paradoxically as we keep advancing in technology, the importance of returning to the basics increases. Many of the techniques described in this paper, and those that are described as essential 21 st century skills [26], are in fact classical techniques that are broadly applicable, and to use the Nassim Nicholas Taleb's terminology, antifragile [55]. Most of the new knowledge becomes obsolete soon with the steadily dropping half-lives of most of engineering knowledge but the core component remains the same. However the core component of engineering and general knowledge remains robust and remains a vital component of modern liberal arts and sciences.

\section{B. About Labs and Practical Work}

One of the biggest challenges facing engineering education and learning is to figure out an effective way of completing lab work in a virtual space through remote access. The use of virtual laboratories is not new in science, technology, and engineering and a detailed review of the tools available can be seen in [56], [57], [58], [59]. While virtual labs and simulations are not a replacement of hands-on experience with real-life devices and tools [58], they can serve the pedagogical ends quite well in the times of disruption where health concerns prohibit physical presence of learners in physical laboratories. Various companies such as MATLAB and National Instruments (NI) offer part of their services through web-based cloud services (e.g., MathWorks Cloud ${ }^{8}$; NI LabVIEW WebVI ${ }^{9}$.

\section{About Digital Divides}

As we adjust to the new normal of online education to respond to the COVID-19 pandemic, we run the risk of producing a new form of social divide. This social divide emerges from the digital divide (some people have access to advanced digital technologies but others don't) due to which digital poverty also translates into an online penalty for some learners. Researchers have shown that this online penalty is minimal for high-achieving and affluent learners who will do well anywhere but quite severe for struggling, underprivileged, and vulnerable students (e.g., younger students, ethnic and racial minorities, and students with low prior achievement).

\footnotetext{
${ }^{8}$ https://www.mathworks.com/solutions/cloud.html

${ }^{9}$ https://www.webvi.io/
}

The shift to online education can potentially accentuate the social divide as students from less-privileged backgrounds could be left behind as students are physically removed from campuses and resources such as libraries and labs. It's important to note that the home environment (is there a quiet space available in the house where the learner can participate in online learning with concentration?) intimately affects the learner's performance apart from computer and network connectivity. Other factors such as the need to take care of siblings can also contribute to an increased online penalty for the less-privileged classes or particular denominations of the population [60]. This can result in a vicious cycle resulting in further impeding the progress of students who are already disadvantaged and behind [61], [62]. The students, particularly those who are disadvantaged in any way, are recommended in such settings to adopt actions described in our paper (such as taking ownership of learning and reaching out for help and support as discussed in $\S \mathrm{VI})$ to avoid the unfortunate situation where the students most in need of support are least likely to reach out for it [63], [64], [65]

\section{Conclusions}

In this paper, we provide a primer for students on how to thrive in volatile, uncertain, complex, and ambiguous (VUCA) times such as the one resulting from the COVID-19 global pandemic. Thriving in the post-COVID-19 engineering education settings requires not only awareness of the Outcome-Based Education (OBE) paradigm underlying modern engineering programs but also significant metacognitive and learning proficiency. In this paper, we have highlighted seven steps that students can adopt to succeed in these times. These seven recommendations, listed pointwise, are that students should: (1) begin with and always keep the end in mind; (2) work on upgrading their metacognitive skills; (3) aim for holistic well-rounded learning; (4) become coachable and develop the skills of self-assessment; (5) take ownership of their learning; (6) focus on developing 'authentic' real-world skills; and (7) develop proficiency of being a lifelong learner. While these tips are aimed at engineering students, we believe that this will also be helpful more generally for students of other disciplines.

\section{REFERENCES}

[1] J. E. Froyd, P. C. Wankat, and K. A. Smith, "Five major shifts in 100 years of engineering education," Proceedings of the IEEE, vol. 100, no. Special Centennial Issue, pp. 1344-1360, 2012.

[2] W. G. Spady, Outcome-Based Education: Critical Issues and Answers. ERIC, 1994

[3] J. Qadir, A. Shafi, A. Al-Fuqaha, A.-E. M. Taha, K.-L. A. Yau, J. Ponciano, S. Hussain, M. A. Imran, S. S. Muhammad, R. N. bin Rais, and et al., "Outcome-based engineering education: A global report of international obe accreditation and assessment practices," Apr 2020. [Online]. Available: edarxiv.org/rde62

[4] "World bank education and covid-19," Apr 2020. [Online] Available: https://www.worldbank.org/en/data/interactive/2020/03/24/ world-bank-education-and-covid-19

[5] S. R. Covey, The 7 habits of highly effective people: Powerful lessons in personal change. Simon and Schuster, 2004.

[6] G. Wiggins and J. McTighe, Understanding by design. ASCD, 2005.

[7] N. Cambron-McCabe, T. Lucas, B. Smith, and J. Dutton, Schools that learn: A fifth discipline fieldbook for educators, parents, and everyone who cares about education. Broadway Business, 2012. 
[8] J. Biggs, "Enhancing teaching through constructive alignment," Higher education, vol. 32, no. 3, pp. 347-364, 1996.

[9] J. Qadir and M. A. Imran, "Learning 101: The untaught basics," IEEE Potentials, vol. 37, no. 3, pp. 33-38, 2018.

[10] S. Dehaene, How We Learn: Why Brains Learn Better Than Any Machine... for Now. Viking, 2020.

[11] C. Newport, How to become a straight-A student: The unconventional strategies real college students use to score high while studying less. Three Rivers Press, 2007.

[12] J. Dunlosky, K. A. Rawson, E. J. Marsh, M. J. Nathan, and D. T. Willingham, "Improving students' learning with effective learning techniques: Promising directions from cognitive and educational psychology," Psychological Science in the Public Interest, vol. 14, no. 1, 2013.

[13] P. C. Brown, H. L. Roediger, and M. A. McDaniel, Make it stick. Harvard University Press, 2014.

[14] B. Carey, How we learn: the surprising truth about when, where, and why it happens. Random House Trade Paperbacks, 2015.

[15] B. Oakley, T. Sejnowski, and A. McConville, Learning how to learn: How to succeed in school without spending all your time studying; a guide for kids and teens. Penguin, 2018.

[16] B. S. Bloom et al., "Taxonomy of educational objectives. vol. 1: Cognitive domain," New York: McKay, pp. 20-24, 1956.

[17] L. W. Anderson and D. E. Krathwohl, A Taxonomy for Learning, Teaching, and Assessing: A Revision of Bloom's Taxonomy of Educational Objectives. Longman, 012001.

[18] E. Simpson, "Educational objectives in the psychomotor domain," Behavioral objectives in curriculum development: Selected readings and bibliography, vol. 60, no. 2, 1971.

[19] J. Qadir, "What every student should know: Seven learning impediments and their remedies," Potentials, IEEE, vol. 34, no. 3, pp. 30-35, 2015.

[20] R. A. Bjork, J. Dunlosky, and N. Kornell, "Self-regulated learning. Beliefs, techniques, and illusions," Annual review of psychology, vol. 64 pp. 417-444, 2013

[21] D. Cabrera and L. Cabrera, Systems thinking made simple. Independently published, 2015.

[22] S. E. Page, The Model Thinker: What You Need to Know to Make Data Work for You. Hachette UK, 2018.

[23] I. Phase et al., Educating the engineer of 2020: Adapting engineering education to the new century. National Academies Press, 2005.

[24] C. T. Munger, Poor Charlie's Almanack: The Wit and Wisdom of Charles T. Munger. Donning Company, 2006.

[25] J. D. Sterman, "All models are wrong: reflections on becoming a systems scientist," System Dynamics Review: The Journal of the System Dynamics Society, vol. 18, no. 4, pp. 501-531, 2002.

[26] Redacted, "Engineering Education, Moving into 2020s: Essential Competencies for Effective 21st Century Electrical \& Computer Engineers, Under Review, Complete Reference To Be Provided Later," Apr 2020.

[27] D. H. Pink, A whole new mind: Why right-brainers will rule the future. Penguin, 2006.

[28] D. Perkins, Making learning whole: How seven principles of teaching can transform education. John Wiley \& Sons, 2010.

[29] D. E. Goldberg and M. Somerville, "A whole new engineer," The coming revolution in Engineering Education. Douglas MI: Threejoy, 2014.

[30] L. V. Morris, "Designing the future in higher education," Innovative Higher Education, vol. 43, no. 5, pp. 321-322, 2018.

[31] R. K. Miller, "Why the hard science of engineering is no longer enough to meet the 21st century challenges," Olin College of Engineering, 2015.

[32] U. National Academy of Engineering, The engineer of 2020: Visions of engineering in the new century. National Academies Press Washington, DC, 2004.

[33] M. Syed, Rebel Ideas: The Power of Diverse Thinking. Hachette UK, 2019.

[34] J. Tranquillo, “The T-shaped engineer," Journal of Engineering Education Transformations, vol. 30, no. 4, pp. 12-24, 2017.

[35] P. Black and D. Wiliam, "Assessment and classroom learning," Assessment in Education: principles, policy \& practice, vol. 5, no. 1, pp. 7-74, 1998.

[36] J. Qadir, A.-E. M. Taha, K.-L. A. Yau, J. Ponciano, S. Hussain, A. Al-Fuqaha, and M. A. Imran, "Leveraging the force of formative assessment \& feedback for effective engineering education," Apr 2020 [Online]. Available: edarxiv.org/a4d5q

[37] J. Hattie and S. Clarke, Visible Learning: Feedback. Routledge, 2018

[38] D. Stone and S. Heen, Thanks for the feedback: the science and art of receiving feedback well. Penguin, 2015, vol. 36, no. 10.

[39] G. Klein, "Performing a project premortem," Harvard business review, vol. 85 , no. 9 , pp. 18-19, 2007
[40] D. E. Goldberg, The entrepreneurial engineer: personal, interpersonal, and organizational skills for engineers in a world of opportunity. John Wiley \& Sons, 2006

[41] J. A. Ruipérez-Valiente, M. Jenner, T. Staubitz, X. Li, T. Rohloff, S. Halawa, C. Turro, Y. Cheng, J. Zhang, I. Despujol et al., "Macro MOOC learning analytics: exploring trends across global and regional providers," in Proceedings of the Tenth International Conference on Learning Analytics \& Knowledge, 2020, pp. 518-523.

[42] B. Trilling and C. Fadel, 21st Century Skills: Learning for Life in Our Times. John Wiley \& Sons, 2009.

[43] B. Oakley, R. M. Felder, R. Brent, and I. Elhajj, "Turning student groups into effective teams," Journal of student centered learning, vol. 2, no. 1, pp. 9-34, 2004.

[44] J. Qadir, K.-L. A. Yau, M. A. Imran, and A. Al-Fuqaha, "Engineering education, moving into 2020s: Essential competencies for effective 21st century electrical and computer engineers,” Apr 2020. [Online]. Available: edarxiv.org/gptse

[45] G. Wiggins, "Ensuring authentic performance," Educative assessment: Designing assessments to inform and improve student performance, pp. $21-42,1998$.

[46] A. Kolmos, F. K. Fink, and L. Krogh, The Aalborg PBL model: progress, diversity and challenges. Aalborg University Press Aalborg, 2004.

[47] J. Dewey, How we think. Courier Corporation, 1997.

[48] E. Mazur, "Assessment: The silent killer of learning," Dudley Herschbach Teacher/Scientist Lecture at Harvard University, Cambridge, MA, 2013.

[49] J. J. Duderstadt, "Engineering for a changing world," in Holistic engineering education. Springer, 2010, pp. 17-35.

[50] C. J. Dede and J. Richards, The 60-Year Curriculum: New Models for Lifelong Learning in the Digital Economy. Routledge, 2020.

[51] D. Goleman, Focus. Bur, 2014.

[52] C. Newport, Deep work: Rules for focused success in a distracted world Hachette UK, 2016

[53] N. Eyal, "Indistractable: How to control your attention and choose your life," Nir and Far, 2019.

[54] D. Rigney, The Matthew effect: How advantage begets further advantage. Columbia University Press, 2010.

[55] N. N. Taleb, Antifragile: Things that gain from disorder. Random House Incorporated, 2012, vol. 3

[56] J. Ma and J. V. Nickerson, "Hands-on, simulated, and remote laboratories: A comparative literature review," ACM Computing Surveys (CSUR), vol. 38, no. 3, pp. 7-es, 2006.

[57] B. Balamuralithara and P. C. Woods, "Virtual laboratories in engineering education: The simulation lab and remote lab," Computer Applications in Engineering Education, vol. 17, no. 1, pp. 108-118, 2009.

[58] T. De Jong, M. C. Linn, and Z. C. Zacharia, "Physical and virtual laboratories in science and engineering education," Science, vol. 340, no. 6130, pp. 305-308, 2013.

[59] V. Potkonjak, M. Gardner, V. Callaghan, P. Mattila, C. Guetl, V. M. Petrović, and K. Jovanović, "Virtual laboratories for education in science, technology, and engineering: A review," Computers \& Education, vol. 95, pp. 309-327, 2016.

[60] Joyce Lau, "Will online education widen Asia's digital divide?, accessed on: 18-May-2020." [Online]. Available: https://www.timeshighereducation.com/news/ will-online-education-widen-asias-digital-divide

[61] J. Reich and M. Ito, "From good intentions to real outcomes: Equity by design in learning technologies," Digital Media and Learning Research Hub, 2017.

[62] J. Reich, C. J. Buttimer, A. Fang, G. Hillaire, K. Hirsch, L. Larke, J. Littenberg-Tobias, R. M. Moussapour, A. Napier, M. Thompson et al., "Remote learning guidance from state education agencies during the covid-19 pandemic: A first look," 2020.

[63] S. Dynarski, "Online courses are harming the students who need the most help," The New York Times, vol. 19, 2018

[64] J. Reich, C. J. Buttimer, A. Fang, G. Hillaire, K. Hirsch, L. Larke, J. Littenberg-Tobias, R. M. Moussapour, A. Napier, M. Thompson, and et al., "Remote learning guidance from state education agencies during the covid-19 pandemic: A first look," Apr 2020. [Online]. Available: edarxiv.org/437e2

[65] Justin Reach, "Keep It Simple, Schools, accessed on: 18-May-2020," An Educational Leadership Special Report - Volume 77, 2020. [Online]. Available: http://www.ascd.org/publications/educational-leadership/ summer20/vol77/num10/Keep-It-Simple,-Schools.aspx 